\title{
CORRESPONDENCE
}

\section{Nitrites in Trouble}

SIR,-In the recent report by your Washington Correspondent (Nature, 239, 63; 1972) on the current arguments concerning the permissibility of nitrite as a food additive in the USA, there are several misrepresentations of fact which we feel should be clarified. Further, the opinions expressed in some of the statements have not been adequately substantiated in our opinion by experimental results.

The contention that nitrite is permitted as a curing agent but not as a preservative is a non sequitur since by definition the act of curing is a form of preservation ("cure": preserve (meat, fruit, tobacco) by salting, drying and so on-Concise Oxford Dictionary). Thus the role of nitrite is not only as a precursor in pigment production but also in development of the typical flavours of cured meat ${ }^{1}$ and in microbiological stability. In particular, nitrite may be essential for the inhibition of germination and outgrowth of spores of Clostridium botulinum. The statement that "there is considerable doubt about the viability of some cured meats as a culture medium for the spores" is surely without foundation. Concentrations of sodium chloride which when used alone are necessary to inhibit the growth from spores of $\mathrm{Cl}$. botulinum, range from 4 to $5 \%$ for type $\mathrm{E}$ and from 8 to $10 \%$ for types $\mathrm{A}$ and $\mathrm{B}$. With modern consumer requirements for low salt bacon and meat products, on purely organoleptic grounds, the level of sodium chloride normally used in cured meats ranges normally from $3.5 \%$ to $5 \%$ on the aqueous phase. In such products, toxin production by $\mathrm{Cl}$. botulinum can occur unless adequate nitrite is present also in the product. The amount of nitrite required to inhibit germination and outgrowth of the spores is dependent upon many factors including the $\mathrm{pH}$ value, the salt content and the degree of heat process (in the case of canned hams) which is given to the product. It is also dependent upon the number and type of spores of $\mathrm{Cl}$. botulinum present ${ }^{2}$. The microbiological stability of pasteurized cured meats may also be influenced by the production of an as yet unidentified antimicrobial agent developed from nitrite ${ }^{3}$.

The statement that meat was involved in only one case of botulism (sic in the USA?) during the period 1950 to 1963 is probably correct. It should be recorded also that no outbreaks of botulism caused by consumption of cured meat products have been recorded in the UK during the present century. However, in France there were sixty-six outbreaks of botulism affecting some 131 persons during the period 1956-1970. Of these, the majority were attributed to consumption of home-cured ham. It is pertinent to note that residual nitrite was not detected in some of the French hams examined (M. Sebald, personal communication, 1971).

Furthermore, in his assessment of the reported controversy over the potential nitrosation in the stomach of secondary amines of dietary or other origin, your correspondent has failed to recognize the paramount importance of the structure of the amine to the outcome. For instance, Dr Mirvish ${ }^{5}$ of the Eppley Institute, University of Nebraska, has found a 185,000 -fold difference in the rates of nitrosation under optimal conditions between the weakly basic piperazine and the strongly basic piperidine. This is reflected in the lack of tumour formation after concurrent feeding of nitrite with a strongly basic amine such as dimethylamine ${ }^{6}$. Whether or not the amines present in foodstuffs or administered as drugs do actually nitrosate in the stomach with the low levels of nitrite available in foodstuffs or present normally in the saliva of the individual must await the outcome of current research, taking account of other reactions competing for the available nitrite.

Naturally your Washington correspondent has dealt exclusively with research, opinions and legislation in the western hemisphere. In so doing, he has had no opportunity to include the extensive programme of research on the role of nitrite in the preservation of meat proceeding at this and other laboratories in the UK and other European countries, particularly Germany.

Yours faithfully,

$$
\begin{aligned}
& \text { B. JaRvis } \\
& \text { C. L. WALters }
\end{aligned}
$$

The British Food Manufacturing

Industries Research Association,

Randalls Road,

Leatherhead.

Surrey

${ }^{1}$ Cho, I. C., and Bratzler, L. J., J. Food Sci., 35, 668 (1970).

2 Roberts, T. A., et al., Ann. Rpt. Meat Research Inst., 1970-71, 77 (1972).

3 Ashrorth, J., and Spencer, R., J. Fd. Technol., 7, 111 (1972).

4 Sebald, M., Bull. Acad. Nat. Med., 154, 26 (1970)
${ }^{5}$ Mirvish, S. S., Proc. Joint Meeting on the Analysis and Formation of Nitrosamines organized by the International Agency for Research on Cancer, Lyon, and Deutsches Krebsforschungszentrum, Heidelberg (1971).

${ }^{6}$ Greenblatt, M., Mirvish, S. S., and So, B. T., J. Nat. Cancer Inst., 46, 1029 (1971).

Our Washington Corerspondent replies :

1. The authors question the distinction between the use of nitrite to fix colour in the curing of meats, and its use as a preservative. They point out that curing implies preservation. Clearly, however, the possible distinction is extremely important in the United States because it is being used by the Center for the Study of Responsive Law and others as a central part of their motion for summary judgment in their suit against the Department of Agriculture. The situation is essentially as follows. The 1958 amendments to the Food and Drug Laws provided exemption for those food additives which are "used in accordance with a sanction or approval granted prior to September 6, 1958, pursuant to the Meat Inspection Act of 1907". This so-called grandfather clause means that such food additives need not go through the stringent testing and review prescribed by the 1958 amendments. The law suit, however, contends that in the 1920s the Department of Agriculture allowed nitrite to be used in the curing of meat "to fix color", and not to prevent the growth of $\mathrm{Cl}$. botulinum. The Department of Agriculture, in its own motion for summary judgment in the case brought by the Center for the Study of Responsive Law, defended use of nitrite largely on the grounds that it prevents growth of $\mathrm{Cl}$. botulinum and its toxin. The plaintiffs are therefore claiming that the USDA is defending the additive for a use which has not been sanctioned and which does not come under the grandfather clause. Their contention is that the USDA can only defend use of nitrite as a colour fixer because that is the only sanctioned use in curing meats. (The Food and Drug Administration has, however, approved use of nitrite as a preservative in the curing of chub fish, but this action was taken after the 1958 amendments and is not part of the argument here.) I maintain therefore that the contention is not necessarily a non sequitur, and it is up to the courts to decide. It is an important issue in the case. 
2. The statement that "there is considerable doubt about the viability of some cured meats as a culture medium for the spores" is based on several different factors. First, spores of $\mathrm{Cl}$. botulinum are extremely rare in meatMr R. Paul Elliott, Acting Director of the USDA Laboratory Services Division, said in hearings before the Fountain subcommittee, for example (Committee hearings, March 16, 17, 18, 29 and 30,1971 , page 236), "The meat industry is fortunate because the putrefactive anaerobe level is very low. Indeed, the level of $\mathrm{Cl}$. botulinum is low almost to the point of extinction." Second, an anaerobic environment is needed for the spores to exist and multiply. Third, types $\mathbf{A}$ and $\mathbf{B}$ Cl. botulinum will not multiply and produce toxins if the meat is refrigerated below $40^{\circ}$ F. Another factor which should be borne in mind is that cooking kills the spores and deactivates the toxins produced, and thus products such as bacon and frankfurters do not present a botulism hazard because they are always cooked before eating. It should be noted that the article clearly pointed out that "even those who are most critical of the FDA's regulatory policies for nitrites accept the possibility that it is valuable in preventing botulism from some products". The chief products to come in this category are canned hams and other canned meats stored in anaerobic conditions.

3. I would deny that "the paramount importance of the structure of the amine to the outcome (of nitrosation)" is central to the controversy I outlined in the article. The fact is that laboratory studies have shown mixtures of nitrites and amine drugs to nitrosate in the stomach. While it is true that some amine drugs nitrosate much more readily than others, it is also a fact that phenmetrazine, a drug used to control appetite, has been found to nitrosate in vivo (Greenblatt et al., Nature New Biology, 236, 236 ; 1972) similarly, aminopyrine has been found to nitrosate in vivo (Lijinsky and Greenblatt, Nature New Biology, 236, 178; 1972) and oxytetracycline, aminopyrine, tolazamide and piperine have all been found to nitrosate with high yield in acidic conditions in the laboratory (Lijinsky et al., Nature, 239, $166 ; 1972$ ). Therefore, to say, as the authors of the letter seem to, that because some drugs do not nitrosate there may not be much of a problem, I think is a wrong attitude to take. It should be noted that the article carefully mentioned that the FDA is not convinced that nitrosation takes place in the stomach, and that the suggestion "is being hotly debated". One other point that is worth noting is that there is a very tricky question of whether or not nitrites, which are not carcinogenic in themselves, are covered by the Delaney Amendment if they are found to lead to the formation of carcinogens in the stomach. If indeed the Delaney Amendment should be interpreted in such a way-and there seems to be a controversy about it-then the structure of the various amines will be totally beside the point. If some amines nitrosate in the human stomach, and the Delaney clause is invoked, then nitrites will be banned without ifs and buts.

4. The above points cover the specific disagreements raised by the authors of the letter, but I think it is worth reiterating the central point of the article-that the FDA has got itself into a bind by not setting sufficient regulations for nitrites (the FDA sets the policy, although the USDA essentially carries it out in the case of meats). There are, I think, two central points. The first is that the 200 p.p.m. level set by the FDA is totally arbitrary and is not based on any scientific evaluation of risk. The second is that no lower limit is set for nitrites, to guard against botulism from meats, although a level is set for fish: this seems to weaken the case made out for nitrites as a preservative. Another point is that the FDA seems to have been extremely lax in its testing programmes.

\section{Seed Research}

SIR,-I am compiling a Directory of research work and research workers in Britain currently investigating problems associated with seed germination and seedling establishment. This includes such topics as seed biochemistry, physiology, pathology or, more generally, seed "quality" (whether from an agronomic or food technological point of view) as well as investigation on soil factors affecting field emergence. The intention is to include only those who will be working on their projects for at least two years.

A questionnaire has already been sent to almost 200 people, but it is extremely difficult to know whether everyone engaged in relevant research has been contacted. Could I appeal, therefore, to anyone in Britain who has not received a questionnaire, but who thinks that he or she should be included in the Directory, to write to me to ask for one?

$$
\begin{aligned}
& \text { Yours faithfully, } \\
& \text { T. W. HEGARTY }
\end{aligned}
$$

Scottish Horticultural Research

Institute,

Invergowrie, Dundee DD2 5DA

\section{HOW TO BUY NATURE}

Volumes start in January, March, May, July, September and November, but subscriptions may begin at any time.

The direct postal price per subscription is:

12 MONTHS (52 issues per title)

$\begin{array}{lcc} & \begin{array}{c}\text { Surface mail } \\ \text { UK and } \\ \text { woridwide }\end{array} & \begin{array}{c}\text { U.S.A, and } \\ \text { Canada }\end{array} \\ \begin{array}{l}\text { Nature (Friday) } \\ \text { Nature + } \\ \text { Nature Physical Science }\end{array} & £ 24 & \$ 48 \\ \begin{array}{l}\text { Nature + } \\ \text { Nature New Biology }\end{array} & £ 24 & \$ 83 \\ \text { All three editions } & £ 29.50 & \$ 108 \\ \text { Annual Index } & \mathbf{E 1} & \$ 3\end{array}$

(Charge for delivery by air mail on application)
Editorial, Advertising and Publishing Offices of NATURE

MACMILLAN JOURNALS LIMITED 4 LITTLE ESSEX STREET, LONDON WC2R 3LF Telephone Number: 01-836 6633. Telegrams: Phusis London WC2R 3LF Telex 262024

MACMILLAN JOURNALS LIMITED

711 NATIONAL PRESS BUILDING WASHINGTON DC 20004

Telephone Number: 202-737 2355. Telex 64280

International Advertisement Manager PETER R. KAVANAGH

MACMILLAN JOURNALS LIMITED 4 LITTLE ESSEX STREET, LONDON WC2R 3LF Telephone Numbers: UK 01-836 6633. USA 202-737 2355

Subscription Department

MACMILLAN JOURNALS LIMITED

BRUNEL ROAD, BASINGSTOKE, HANTS

Telephone Number: Basingstoke 29242

Classified advertisements

T. G SCOTT \& SON, LIMITED

1 CLEMENT'S INN, LONDON WC2A $2 E D$

Telephone Number: 01-242 6264/01-405 4743

Telegrams; Textualist London WC2A 2ED 